\title{
Comentários sobre o Artigo de Girardi e cols.: Custos em Cirurgia Cardíaca
}

Paulo R. Benchimol-Barbosa

Hospital Universitário Pedro Ernesto - Universidade do Estado do Rio de Janeiro; Hospital Central Aristarcho Pessoa; Corpo de Bombeiros Militar do Estado do Rio de Janeiro, Rio de Janeiro, RJ - Brasil

\section{Senhor Editor,}

Li com interesse o artigo de Girardi e cols., no qual os autores analisam o impacto de duas técnicas cirúrgicas sobre os custos hospitalares relacionados aos procedimentos ${ }^{1}$. Gostaria de congratular os autores pela ousadia em abordar assunto controverso e pela clareza e objetividade apresentadas.

O custeio de cirurgias de revascularização do miocárdio em hospitais credenciados pelo Sistema Único de Saúde (SUS), seja com ou sem circulação extracorpórea, parece ter impacto negativo no número de cirurgias eletivas realizadas, como é o caso de nossa instituição. Aparentemente, o custeio oferecido pelo convênio (SUS) não cobre o custo total do procedimento, o que, eventualmente, acarreta falta de pagamento de fornecedores e contratantes. A consequência imediata é a limitação do número de cirurgias cardíacas realizadas, com a formação de longas filas de espera. A curto e médio prazo, possivelmente, impactam-se os desfechos dos pacientes que aguardam o procedimento.

Nesse contexto, Oliveira e cols. ${ }^{2}$, em excelente artigo publicado nos Arquivos Brasileiros de Cardiologia, constataram o elevado custo social relacionado aos procedimentos cardiológicos invasivos (cirúrgicos ou intervencionistas) realizados em instituições credenciadas pelo SUS no Estado do Rio de Janeiro, entre 1999 e 2003, no qual verificaram a elevada morbimortalidade intra-hospitalar, muito acima dos padrões de qualidade aceitos.

Olhando os dois lados da situação, parece que o aparente paradoxo se completa: o custeio inadequado dos gastos hospitalares fornecido pelo convênio reflete-se diretamente na qualidade dos procedimentos e, consequentemente, nos desfechos da internação. O que fazer? Procedimentos cirúrgicos eficientes, com baixo custo intra-hospitalar e adequada eficácia terapêutica têm posição de destaque e devem ser considerados na gestão de cuidados assistenciais. Não-obstante, a melhora dos indicadores de qualidade em saúde, como índices de morbimortalidade intra-hospitalar, deve ser precedida da adequada gestão dos cuidados assistenciais e do apropriado custeio dos procedimentos realizados.

Paz e Bem.

\section{Palavras chave}

Honorários e preços, custos de cuidados de saúde, cirurgia torácica.

Correspondência: Paulo R. Benchimol-Barbosa

Rua Pompeu Loureiro, 36/702, 22061-000, Rio de Janeiro, RJ - Brasil E-mail: pbarbosa@cardiol.br

Artigo recebido em 02/12/08; revisado recebido em 05/12/08; aceito em 05/12/08.

\section{Referências}

1. Girardi PB, Hueb W, Nogueira CR, Takiuti ME, Nakano T, Garzillo CL, et al. Comparative costs between myocardial revascularization with or without extracorporeal circulation. Arq Bras Cardiol. 2008; 91 (6): 369-76.

2. Oliveira GM, Klein CH, Souza e Silva NA, Godoy PH, Fonseca TM. Ischemic heart disease lethalities in the state of Rio de Janeiro between 1999 and 2003. Arq Bras Cardiol. 2006; 86 (2): 131-7.

\section{Resposta do autor}

\section{Prezado Senhor,}

Recebi o direito de resposta do Editor em relação ao artigo "Custos comparativos entre a revascularização miocárdica com e sem circulação extracorpórea"1 ${ }^{\prime}$. Quero agradecer os comentários e concordar inteiramente com as colocações do missivista.

De fato, nosso sistema de saúde foi transformado em monopólio estatal, em que a maioria esmagadora dos enfermos é refém do Sistema Único de Saúde (SUS), sem opção qualitativa de escolha e sem condições econômicas para acesso ao tratamento por meio da saúde suplementar ou dos serviços privados.

Dessa forma, o SUS faz de conta que remunera o atendimento, e os prestadores de assistência médica fazem de conta que recebem a remuneração. Pratica-se, por outro lado, um atendimento da melhor qualidade dentro das condições impostas pelo SUS. As discussões sobre a remuneração da prestação de serviços médicos merecem profundas e desapaixonadas reflexões sobre a quem cabe esse monopólio e se é a própria sociedade que deve regular essa atividade.

O que não se pode aceitar é esse estado de arbítrio entre o estado e os prestadores de serviços de saúde. Senão vejamos: nossa pesquisa, que objetivou avaliar os custos hospitalares de um procedimento de alta complexidade, somente abordou situações concretas dos preços de órteses e próteses, sem levar em conta os preços efetivamente pagos pelo hospital. Como se sabe, nem sempre os preços remuneram os custos.

Por causa desse monopólio, o SUS pratica uma remuneração arbitrária e diferente para o mesmo procedimento e para cada hospital. Em nosso hospital, trabalhamos com o regime de um teto de pagamento fixo mensal sobre toda a atividade assistencial, independentemente da quantidade e do tipo de atendimento praticado.

Assim, quando realizamos o maior número de investigação diagnóstica e também terapêutica sequencial que o limite monetário permite, vamos impor à instituição um prejuízo adicional sobre o já deficiente programa de pagamentos. 
Caracteriza-se, assim, um contrato de risco em que o risco é somente de um lado.

Nessa linha de raciocínio, vale lembrar que as complicações operatórias que exigem recursos de alta complexidade, tais como balão intra-aórtico e circuito de hemodiálise, entre outros, não serão remuneradas pelo SUS.

Outra forma arbitrária de remuneração praticada pelo SUS refere-se ao pagamento por cotas de procedimentos. Sabe-se que o SUS remunera um número limitado de exames ou procedimentos para cada hospital, de acordo com sua capacidade de atendimento. Pacientes atendidos acima desse teto ou na presença de complicações do procedimento não serão remunerados.

Isso sem discutir inúmeros avanços tecnológicos não aceitos pelo SUS, não sendo, portanto, remunerados. Essa prática estimulou o sistema de planos de saúde complementar a também não remunerar os procedimentos não pagos pelo SUS. Exemplo disso ocorre com a implantação dos stents farmacológicos.

Assim, conforme o missivista classificou como ousadia nosso estudo de custos, considero esse estudo a maneira simbólica de se quantificar quanto custa para o SUS determinado procedimento. Dessa forma, ficamos sem saber o que é custo, o que é preço, o que é valor. Não para a sociedade, não para o paciente, não para o hospital.

\section{Whady Hueb}

\section{Referências}

1. Girardi PB, Hueb W, Nogueira CR, Takiuti ME, Nakano T, Garzillo CL, et al. Comparative costs between myocardial revascularization with or without extracorporeal circulation. Arq Bras Cardiol. 2008; 91 (6): 369-76. 